\title{
Importance of Static Correction and Damping in the Analysis of a Cable-Stayed Bridge Subjected to Displacement Loading
}

\author{
Çağlayan Hızal ${ }^{1}$ and Gürsoy Turan ${ }^{2}$
}

\begin{abstract}
Cable-stayed bridges with long spans are excited by different support vibrations on both sides of the main span. Therefore, a realistic seismic structural analysis of the bridge must involve multiple-support excitation. The dynamic equation of motion, in which all degrees of freedom are solved at once, can be solved directly. A modal analysis might also be possible, but care must be taken with the number of modes used in the analysis. If the ground motion is described in terms of displacement and velocity, which is referred to as displacement loading, then a static correction that will account for the unconsidered higher modes must be performed. In this study, the procedure of multiple-support excitation through the use of modal transformation is explained in detail. The effects of changes in damping levels that affect the analysis results are investigated by using the static correction method in displacement loading. An example is given to illustrate the mentioned problem by using a finite-element model of the cable-stayed Bill Emerson Memorial Bridge. DOI: 10.1061/(ASCE)BE.1943-5592.0001041. C) 2017 American Society of Civil Engineers.
\end{abstract}

Author keywords: Multiple-support excitation; Static correction method; Damping effect; Modal analysis; Displacement loading.

\section{Introduction}

The seismic analysis of structures that have long spans, such as cable-stayed or suspension bridges, pipelines, and domes, need further consideration when modal superposition in conjunction with ground displacement is to be used. As it is known from the literature, if the supports of the structure are far apart, a traveling wave results in different support excitations (Su et al. 2007; Zhang et al. 2009).

Displacement loading excites high-frequency modes (Wilson 2002), and errors are likely to occur if these high-frequency modes are omitted in the modal analysis. To circumvent this problem, several studies have established an analysis procedure to minimize the computational model errors in the case of displacement loading. Tsai (1998) proposed the static correction method to provide convergence between the solutions obtained by displacement-loading and conventional acceleration-loading analyses. Tsai (1998) gave examples to illustrate the effect of the static correction method on the results of convergence analysis obtained by displacement and acceleration loadings for uniform excitation. Wilson (2002) described the general characteristics of displacement loading and probable numerical errors that emerge in the closed-form solution. Wilson (2002) highlighted the effect of damping on the consistency of analysis. Furthermore, the author noted that as the damping ratio increased, the analysis results were increasingly inconsistent. $\mathrm{Li}$ and Yang (2008) analyzed the seismic response of a long continuous rigid-frame bridge subjected to multiple-support excitation by displacement loading. They used the direct integration method, which provides a closed-form solution without modal analysis by

\footnotetext{
${ }^{1}$ Research Assistant, Ph.D. Candidate, Civil Engineering Dept., Izmir Institute of Technology, Urla, Izmir 35430, Turkey (corresponding author). E-mail: caglayanhizal@iyte.edu.tr

${ }^{2}$ Assistant Professor, Ph.D., Civil Engineering Dept., Izmir Institute of Technology, Urla, Izmir 35430, Turkey. E-mail: gursoyturan@iyte.edu.tr

Note. This manuscript was submitted on August 30, 2016; approved on December 8, 2016; published online on February 22, 2017. Discussion period open until July 22, 2017; separate discussions must be submitted for individual papers. This paper is part of the Journal of Bridge Engineering, (C) ASCE, ISSN 1084-0702.
}

neglecting the damping effect. Tian and Yang (2009) compared acceleration and displacement loading by using the direct integration solution and focused on the numerical errors caused by the integration time step and their effect on the convergence analysis by neglecting the damping effects. Yau and Frýba investigated the response of suspension bridges with moving loads against multisupport displacement motion (Yau and Frýba 2007; Frýba and Yau 2009; Yau 2009). In their studies, these authors modeled the center span of a suspension bridge as an equivalent Euler-Bernoulli beam that includes the stiffness of the cables for dynamic analysis. Du et al. (2012) analyzed a coupled bridge-train system that was subjected to displacement ground motion. In their study, a modal analysis was performed to obtain the dynamic response of the bridge-train system. However, the effect of static correction was overlooked.

Multisupport-excitation analysis is well known and widely used by engineers, and acceleration loading is generally used in such applications (Soyluk 2004; Abdel Raheem et al. 2011; Ye et al. 2012; Jiao et al. 2013; Wang and Kiureghian 2014; Surh et al. 2015). Cui and Gao (2011) investigated the traveling-wave effect in long-span cable-stayed bridges, and they concluded that research on long-span cable-stayed bridges needs to not only account for the traveling wave effect but also include wave refraction, reflection, and scattering in different media. Li et al. (2014) investigated the effect of support flexibility on seismic responses of a reticulated dome under multiple-support excitation with spatially correlated and coherent excitations. The properties of spatial correlation and coherency of multiple-support excitations were highlighted, and the study revealed that coherency affected the seismic response. Wang et al. (2015) investigated the apparent wave-velocity effect on the seismic performance of the Taizhou suspension bridge. They presented a review of the critical issues in analyzing the traveling-wave effect and proposed characteristics of the shear force and bending moment distributions of the towers and the traveling-wave effect on those force distributions.

In this study, the modal analysis procedure for long-span structures subjected to displacement loading is analyzed by using a finite-element model of the cable-stayed Bill Emerson Memorial Bridge, which has been studied by many researchers (Dyke et al. 2003; Caicedo et al. 2003; Koh and Dyke 2007; Domaneschi and 
Martinelli 2014; De Mari et al. 2015). The static correction method, applied for consistency of the displacement and the base shear response, is investigated. The pseudostatic effects of the support reactions are also studied. The compatibility of mass, stiffness, and static-load participation ratios with the exact modal variation of displacement and base shear force response are investigated. In addition, the effect of damping in the modal analysis is evaluated. To the knowledge of the authors, neither a comprehensive investigation of modal contributions on analysis results nor a study on damping in multiple-support displacement loading has been performed so far.

\section{Formulation of Multiple-Support Excitation}

Two different methods are used to solve the equation of motion of long-span bridges subjected to support excitation, the displacementloading and acceleration-loading methods. They are classified according to the construction of the external load function. In conventional acceleration loading, the external load function is obtained by multiplying the mass matrix of unconstrained degrees of freedom (DOF), the ground acceleration, and its expansion vector (Chopra 2013). Because the mass matrix is associated with this procedure, this loading type can be considered mass proportional. In displacement loading, the external load function is constructed by multiplying the stiffness matrix and the displacement vector of the constrained (support) DOF. Therefore, this type of loading can be considered stiffness proportional.

The equation of motion of a long-span structure subjected to support excitation can be written as

$$
\begin{aligned}
{\left[\begin{array}{cc}
M & M_{g} \\
M_{g}^{T} & M_{g g}
\end{array}\right] } & +\left\{\begin{array}{c}
\ddot{y}^{t}(t) \\
\ddot{y}_{g}(t)
\end{array}\right\}+\left[\begin{array}{cc}
C & C_{g} \\
C_{g}^{T} & C_{g g}
\end{array}\right]\left\{\begin{array}{c}
\dot{y}^{t}(t) \\
\dot{y}_{g}(t)
\end{array}\right\} \\
& +\left[\begin{array}{cc}
K & K_{g} \\
K_{g}^{T} & K_{g g}
\end{array}\right]\left\{\begin{array}{l}
y^{t}(t) \\
y_{g}(t)
\end{array}\right\}=\left\{\begin{array}{c}
0 \\
F_{g}(t)
\end{array}\right\}
\end{aligned}
$$

where $M, C$, and $K=$ mass, damping, and stiffness matrices of unconstrained DOF, respectively; $M_{g g}, C_{g g}$, and $K_{g g}=$ mass, damping, and stiffness matrices of constrained DOF, respectively; and $M_{g}, C_{g}$, and $K_{g}=$ coupling mass, damping, and stiffness matrices of constrained and unconstrained DOF, respectively. $y^{t}(t)$ and $y_{g}(t)$ denote the absolute displacement vector of unconstrained and constrained DOF, respectively. $F_{g}(t)$ denotes the total force acting on the support DOF. The equation of motion given in Eq. (1) can be separated into two parts as follows:

$$
\begin{gathered}
M \ddot{y}^{t}(t)+C \dot{y}^{t}(t)+K y^{t}(t)=-K_{g} y_{g}(t)-C_{g} \dot{y}_{g}(t) \\
-M_{g} \ddot{y}_{g}(t) \\
\left\{M_{g}^{T} \ddot{y}^{t}(t)+M_{g g} \ddot{y}_{g}(t)\right\}+\left\{C_{g}^{T} \dot{y}^{t}(t)+C_{g g} \dot{y}_{g}(t)\right\} \\
+\left\{K_{g}^{T} y^{t}(t)+K_{g g} y_{g}(t)\right\}=F_{g}(t)
\end{gathered}
$$

Eqs. (2) and (3) denote the equation of motion of the unconstrained and constrained DOF, respectively.

In common practice, the third term on the right-hand side of Eq. (2) is much smaller than the first and second terms. Thus, the third term is neglected [Eq. (4)].

$$
M \ddot{y}^{t}(t)+C \dot{y}^{t}(t)+K y^{t}(t)=-K_{g} y_{g}(t)-C_{g} \dot{y}_{g}(t)
$$

Because the right side of Eq. (4) includes both ground displacement and velocity input, the external load can be referred to as displacement and velocity loading. For low damping values, the second term of the right side of Eq. (4) is negligible. In this case, the external dynamic loading is referred to as displacement loading in the literature. Then, the equation of motion of unconstrained DOF takes the following form:

$$
M \ddot{y}^{t}(t)+C \dot{y}^{t}(t)+K y^{t}(t)=-K_{g} y_{g}(t)
$$

In dynamic analysis, the relative displacement vectors of unconstrained DOF are used in general, and therefore, the external load function consists of the mass matrix multiplied by the ground-acceleration vector. As a result, this type of loading is called mass proportional and/or acceleration loading. If the equation of motion is based on relative displacements, then the absolute displacement can be separated as shown by Chopra (2013).

$$
\left\{\begin{array}{l}
y^{t}(t) \\
y_{g}(t)
\end{array}\right\}=\left\{\begin{array}{c}
y^{s}(t) \\
y_{g}(t)
\end{array}\right\}+\left\{\begin{array}{c}
y(t) \\
0
\end{array}\right\}
$$

and

$$
\begin{aligned}
& \dot{y}^{t}(t)=\dot{y}^{s}(t)+\dot{y}(t) \\
& \ddot{y}^{t}(t)=\ddot{y}^{s}(t)+\ddot{y}(t)
\end{aligned}
$$

where $y^{s}(t)=$ pseudostatic displacement of unconstrained DOF that arises because of movement of the constrained DOF; and $y(t)=$ relative displacement vector of unconstrained DOF with respect to the pseudostatic configuration. Thus, the equation of motion is written according to the relative coordinates for acceleration loading per Tsai (1998)

$$
M \ddot{y}(t)+C \dot{y}(t)+K y(t)=-M \ell \ddot{y}_{g}(t)
$$

where $\ell$ is called the influence matrix, which is expressed as follows:

$$
\ell=-K^{-1} K_{g}
$$

The pseudostatic displacements are written as follows:

$$
y^{s}(t)=\ell y_{g}(t)
$$

\section{Modal Analysis Procedure}

\section{Modal Analysis Formulation of Displacement Loading}

The total displacement vector of the structural unconstrained DOF can be expressed as the superposition of its modal contributions

$$
y^{t}(t)=\sum_{i=1}^{N} \Phi_{i} Y_{i}^{t}(t)
$$

where $\Phi_{i}, Y_{i}^{t}(t)$, and $N=i$ th mode shape vector, the $i$ th normal coordinate, and the number of unconstrained DOF, respectively. Thus, the equation of motion obtained for displacement and velocity loading can be written in the following form by substituting Eq. (11) into Eq. (4): 


$$
\begin{aligned}
M \sum_{i=1}^{N} \Phi_{i} \ddot{Y}_{i}^{t}(t) & +C \sum_{i=1}^{N} \Phi_{i} \dot{Y}_{i}^{t}(t)+K \sum_{i=1}^{N} \Phi_{i} Y_{i}^{t}(t) \\
& =-K_{g} y_{g}(t)-C_{g} \dot{y}_{g}(t)
\end{aligned}
$$

and premultiplying by $\Phi_{j}^{T}$

$$
\bar{M}_{i} \ddot{Y}_{i}^{t}(t)+\bar{C}_{i} \dot{Y}_{i}^{t}(t)+\bar{K}_{i} Y_{i}^{t}(t)=-\Phi_{i}^{T} K_{g} r u_{g}(t)-\Phi_{i}^{T} C_{g} r \dot{u}_{g}(t)
$$

$$
\begin{aligned}
\bar{M}_{i} & =\Phi_{i}^{T} M \Phi_{i} \\
\bar{C}_{i} & =\Phi_{i}^{T} C \Phi_{i} \\
\bar{K}_{i} & =\Phi_{i}^{T} K \Phi_{i}
\end{aligned}
$$

and

$$
y_{g}(t)=r u_{g}(t)
$$

where $\bar{M}_{i}, \bar{C}_{i}$, and $\bar{K}_{i}=$ generalized mass, damping, and stiffness, respectively, of the $i$ th mode; and $u_{g}(t)$ and $r=$ ground displacement and its expansion vector, respectively. The expansion vector can be written as

$$
r=\left[\begin{array}{lllll}
r_{1} & r_{2} & r_{3} & , \ldots, & r_{N g}
\end{array}\right]^{T}
$$

where $r_{1}$ though $r_{N g}=$ scalar values in the case of uniform excitation that indicate the ground-motion effects on the specific support DOF; and $N_{g}=$ number of constrained DOF. In this study, only unidirectional investigation is performed. Thus, $r_{i}=1$ for DOF along the longitudinal direction, and otherwise, $r_{i}=0$.

If the damping force at the right side of Eq. (13) is neglected, then the equation of motion of the $i$ th mode can be written as

$$
\ddot{\mathrm{Y}}_{i}^{t}(t)+2 \xi \omega_{i} \dot{\mathrm{Y}}_{i}^{t}(t)+\omega_{i}^{2} \mathrm{Y}_{i}^{t}(t)=-\Gamma_{i}^{K} u_{g}(t)
$$

where $\Gamma_{i}^{K}=$ modal participation factor of the $i$ th mode.

$$
\Gamma_{i}^{K}=\frac{\Phi_{i}^{T} K_{g} r}{\bar{M}_{i}}
$$

The equivalent external load vector acting on the unconstrained DOF is determined by the multiplication of $K_{g}$ and the ground displacement while neglecting the velocity input; therefore, this loading type can be considered stiffness proportional. The right side of Eq. (18) has units of force per mass. The unit of $\Gamma_{i}^{K}$ is 1 divided by time squared, which brings to mind $\omega_{i}^{2}$. Therefore, $\Gamma_{i}^{K}$ and the driving force in Eq. (17) can be considered modal stiffness proportional.

In Eq. (18), the vector $K_{g} \times r$ denotes the spatial distribution of earthquake forces caused by uniform ground-displacement loading, which can be decomposed into its modal contributions.

$$
K_{g} r=S^{K}=\sum_{i=1}^{N} S_{i}^{K}
$$

By a reverse calculation in Eq. (19), the effective modal stiffness of the $i$ th mode can be written as follows:

$$
S_{i}^{K}=\Gamma_{i}^{K} M \Phi_{i}
$$

To obtain a cumulative stiffness participation ratio for a number of considered modes, an energy approach is developed. The vector
$S^{K}$ corresponds to the force of the structural DOF caused by uniform unit ground displacement, and $K^{-1} \times S^{K}$ is the corresponding structural displacement vector. Thus, the total structural energy is

$$
E=\frac{1}{2}\left(K^{-1} S^{K}\right)^{T} S^{K}=-\frac{1}{2}(\ell r)^{T} S^{K}
$$

Accordingly, the relative energy ratio accumulated by the first $n$ modes can be written as

$$
K_{n}^{s}=\frac{(\ell r)^{T} \sum_{i=1}^{n} \Gamma_{i}^{K} M \Phi_{i}}{(\ell r)^{T} S^{K}}
$$

where Eq. (22) also corresponds to the cumulative static-load participation ratio of displacement loading. In acceleration loading, however, the external load consists of the mass multiplied by the ground acceleration. A similar energy approach can be used to develop a relative energy ratio for this type of loading in which the force is now based on uniform unit acceleration, and the corresponding displacement is equivalent to the uniform unit acceleration divided by $\omega_{i}^{2}$. Thus, the resultant normalized value given in Eq. (23) corresponds to the cumulative static-load participation ratio of acceleration loading

$$
M_{n}^{s}=\frac{\left(K^{-1} S^{M}\right)^{T} \sum_{i=1}^{n} \Gamma_{i}^{M} M \Phi_{i}}{\left(K^{-1} S^{M}\right)^{T} M \ell r}
$$

where $S^{M}$ denotes the spatial distribution of earthquake forces caused by uniform ground acceleration (Chopra 2013).

$$
S^{M}=M \ell r
$$

Note that the modal participation factor in Eq. (23) is written as follows for acceleration loading:

$$
\Gamma_{i}^{M}=\frac{\Phi_{i}^{T} M \ell r}{\bar{M}_{i}}
$$

In addition, the effect of the widely used cumulative-effective mass-participation ratio shows the difference with respect to the energy approach.

$$
M_{n}^{e}=\frac{(\ell r)^{T} \sum_{i=1}^{n} \Gamma_{i}^{M} M \Phi_{i}}{(\ell r)^{T} M \ell r}
$$

where the vector of $(\ell r)^{T}$ represents the unconstrained DOF based on unit acceleration along the $x$-directional (longitudinal) constrained DOF.

In addition, if the cumulative effective stiffness participation, $K_{n}^{e}$, is obtained in the same manner, then the result will be equivalent to the static-load participation ratio of displacement loading, as given in Eq. (22).

The variation of the static-load participation ratio denotes the energy contribution of modes on vibration. In contrast, cumulative effective mass and stiffness participation ratio represent the total load contribution of the vibration modes. In common practice, $90 \%$ participation is sufficient for reasonable convergence to an exact solution. For acceleration loading, only a few lowfrequency modes are usually enough to accomplish this 
requirement. In displacement loading, however, the number of modes that need to be considered should be close to the number of unconstrained DOF because the higher modes are effective on this type of loading.

In the case of the support DOF subjected to different ground displacements, the right side of Eq. (17) can be written as

$$
-\bar{\Gamma}_{i}^{K} y_{g}(t)
$$

where

$$
y_{g}(t)=\left[\begin{array}{lllll}
u_{g, 1}(t) & u_{g, 2}(t) & u_{g, 3}(t) & , \ldots, & u_{g, N_{g}}(t)
\end{array}\right]^{T}
$$

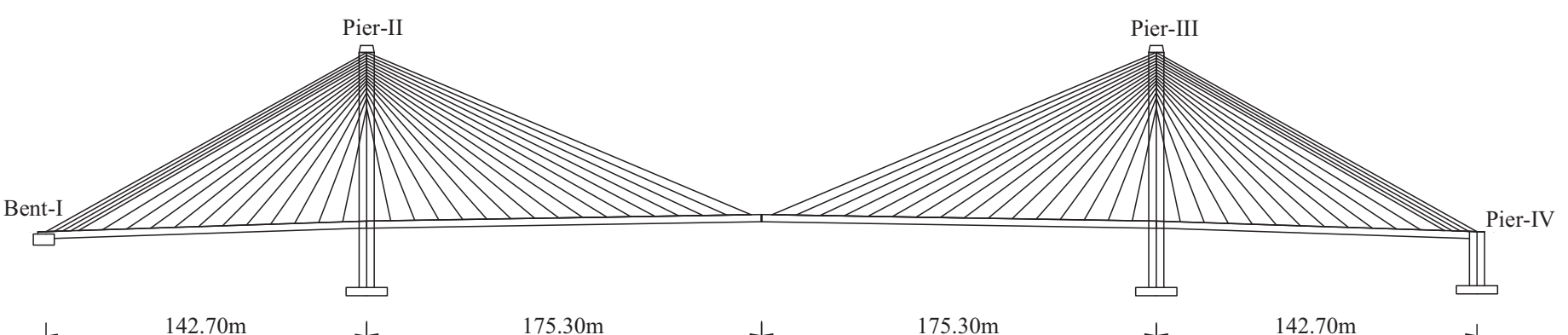

Fig. 1. Schematic view of the Bill Emerson Memorial Bridge where $u_{g, 1}(t), \ldots, u_{g, N g}(t)=$ prescribed displacement of the corresponding support DOF. $\bar{\Gamma}_{i}^{K}$ is the vector of size $1 \times N_{g}$ and denotes the modal participation vector of the $i$ th mode, and it is defined as follows:

$$
\bar{\Gamma}_{i}^{K}=\frac{\Phi_{i}^{T} K_{g}}{\bar{M}_{i}}
$$

\section{Static Correction Method}

As mentioned earlier, the equations of motion obtained for displacement and acceleration loadings are different from each other

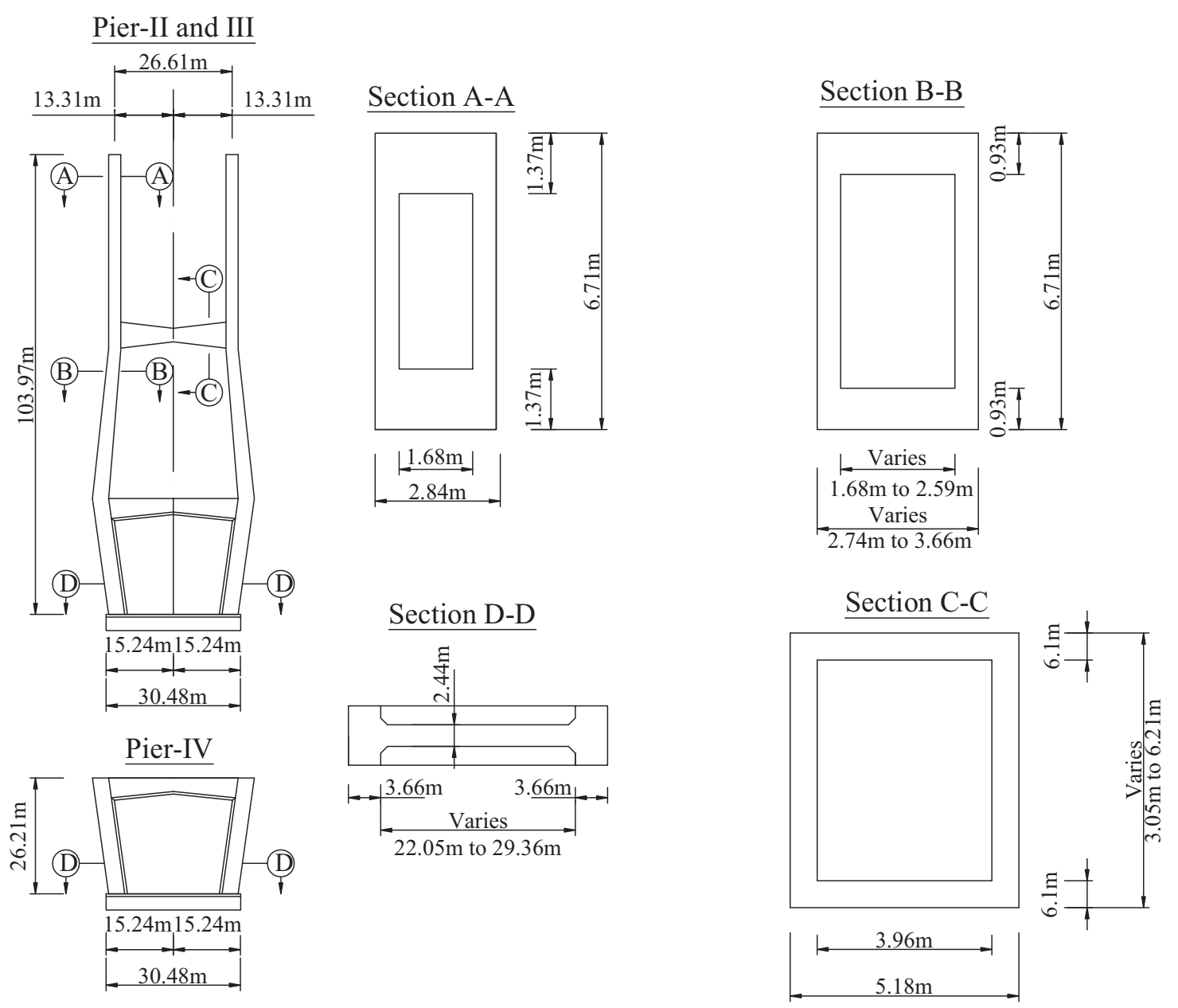

Fig. 2. Section details of Piers II, III, and IV 


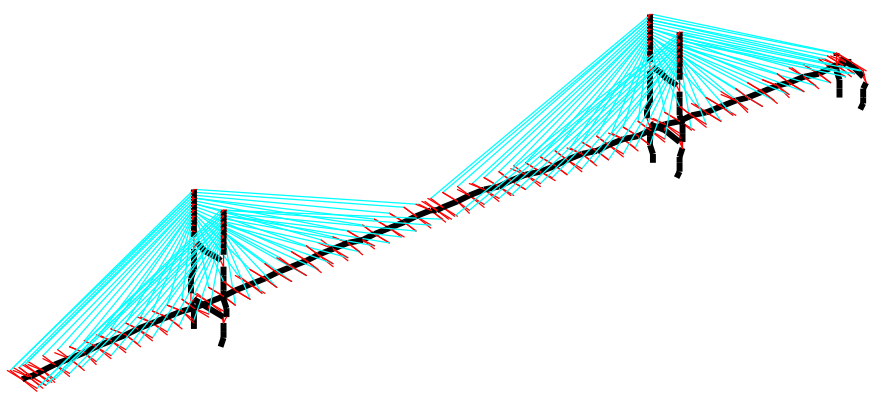

Fig. 3. Finite-element model of the Bill Emerson Memorial Bridge

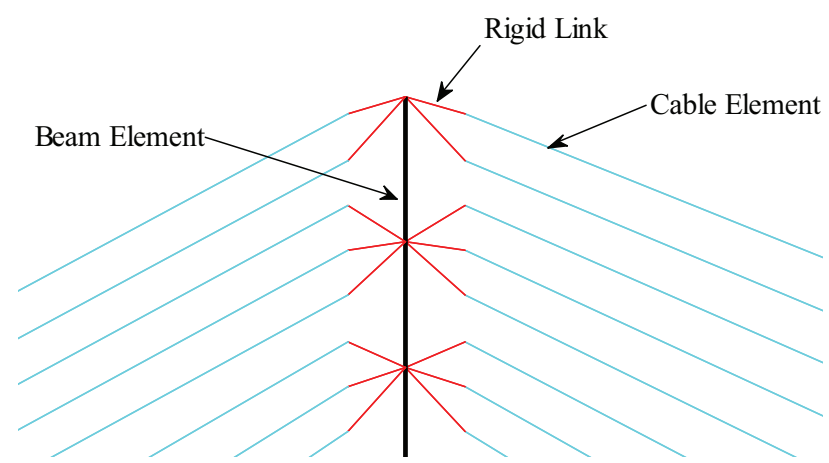

(a) because of the construction of the effective external load. The solutions to equations of motion obtained by implicit methods are identical for displacement and acceleration loadings. To the contrary, if not all modes are considered in the dynamic analysis, the solution obtained by modal superposition might not be consistent with that for displacement loading, which excites higher modes. The spatial distribution of the effective external load is defined as a matrix for acceleration loading

$$
\bar{S}^{M}=M \ell=\sum_{i=1}^{N} \bar{S}_{i}^{M}=\sum_{i=1}^{N} M \Phi_{i} \bar{\Gamma}_{i}^{M}
$$

where

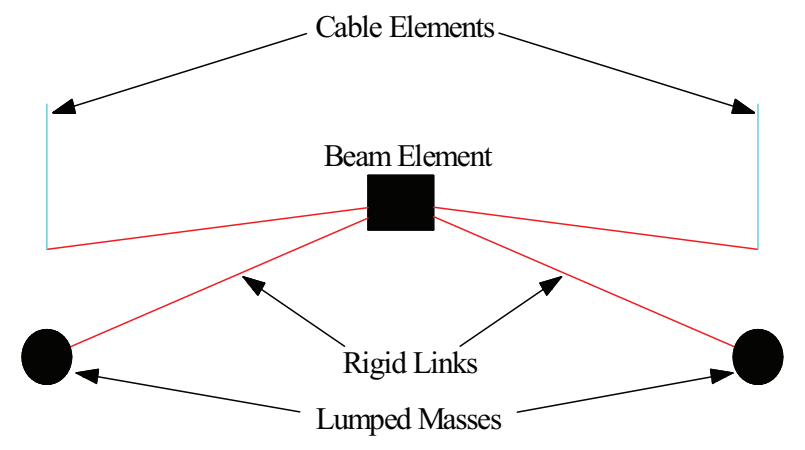

(b)

Fig. 4. Connection details of the finite-element model: (a) tower cable; (b) deck cable

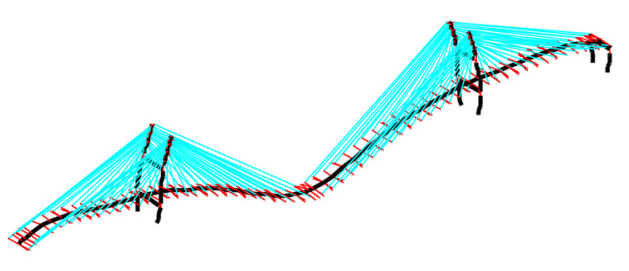

(a)

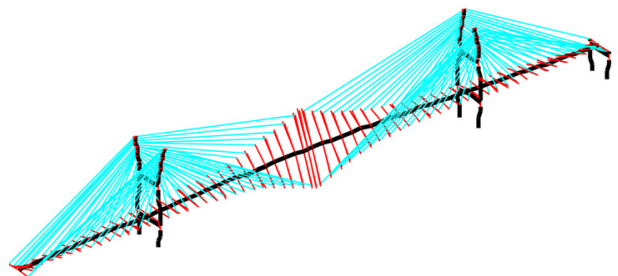

(c)

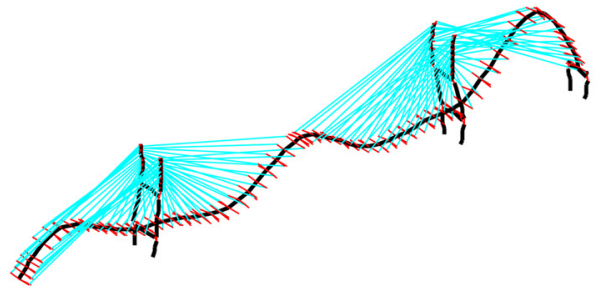

(e)

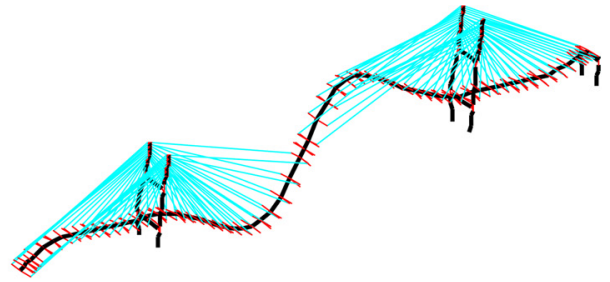

(b)

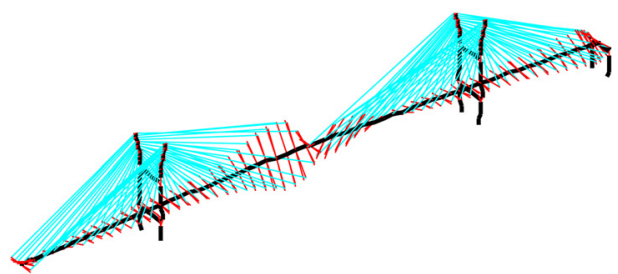

(d)

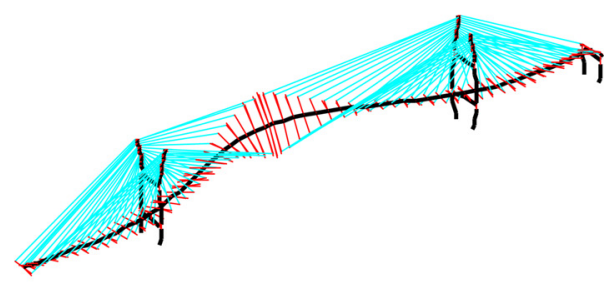

(f)

Fig. 5. Free-vibration mode shapes of the finite-element model of the Bill Emerson Memorial Bridge: (a) Mode Shape 1 (vertical); (b) Mode Shape 2 (vertical); (c) Mode Shape 3 (torsional); (d) Mode Shape 4 (torsional); (e) Mode 5 (vertical); (f) Mode 6 (lateral and torsional) 


$$
\bar{\Gamma}_{i}^{M}=\frac{\Phi_{i}^{T} M \ell}{\bar{M}_{i}}
$$

Then, the influence matrix, $\ell$, can be obtained alternatively as

$$
\ell=\sum_{i=1}^{N} \Phi_{i} \bar{\Gamma}_{i}^{M}
$$

If only $n$ modes are considered, then an error term persists

$$
\ell=\sum_{i=1}^{n} \Phi_{i} \bar{\Gamma}_{i}^{M}+\text { error }
$$

This error reflects the pseudostatic displacement as follows:

$$
y_{\text {error }}^{s}=\left(\ell-\sum_{i=1}^{n} \Phi_{i} \bar{\Gamma}_{i}^{M}\right) y_{g}(t)
$$

Eq. (34) corresponds to the structural pseudostatic displacement caused by unconsidered high-frequency modes in displacement loading. These modes are not considered in a regular modal analysis (if $n<N$ ), but they are essential for obtaining a correct structural response (Tsai 1998). Thus, the total displacement vector can be updated by using the following equation:

$$
y^{t}(t)^{S C}=\left(\ell-\sum_{i=1}^{n} \Phi_{i} \bar{\Gamma}_{i}^{M}\right) y_{g}(t)+\sum_{i=1}^{n} \Phi_{i} \mathrm{Y}_{i}^{t}(t)
$$

Table 1. Natural Frequencies of First Six Modes and Comparison with Earlier Studies

\begin{tabular}{lcccc}
\hline \multirow{2}{*}{$\begin{array}{l}\text { Mode } \\
\text { number }\end{array}$} & $\begin{array}{c}\text { Present } \\
\text { study }\end{array}$ & $\begin{array}{c}\text { Turan et al. } \\
(2009)\end{array}$ & $\begin{array}{c}\text { Caicedo et al. } \\
(2003)\end{array}$ & $\begin{array}{c}\text { Koh and Dyke } \\
(2007)\end{array}$ \\
\hline 1 & 0.267 & 0.267 & 0.290 & 0.290 \\
2 & 0.379 & 0.372 & 0.370 & 0.380 \\
3 & 0.452 & 0.455 & 0.468 & 0.440 \\
4 & 0.526 & 0.502 & 0.516 & 0.480 \\
5 & 0.566 & 0.565 & 0.581 & 0.600 \\
6 & 0.625 & 0.645 & 0.649 & 0.660 \\
\hline
\end{tabular}

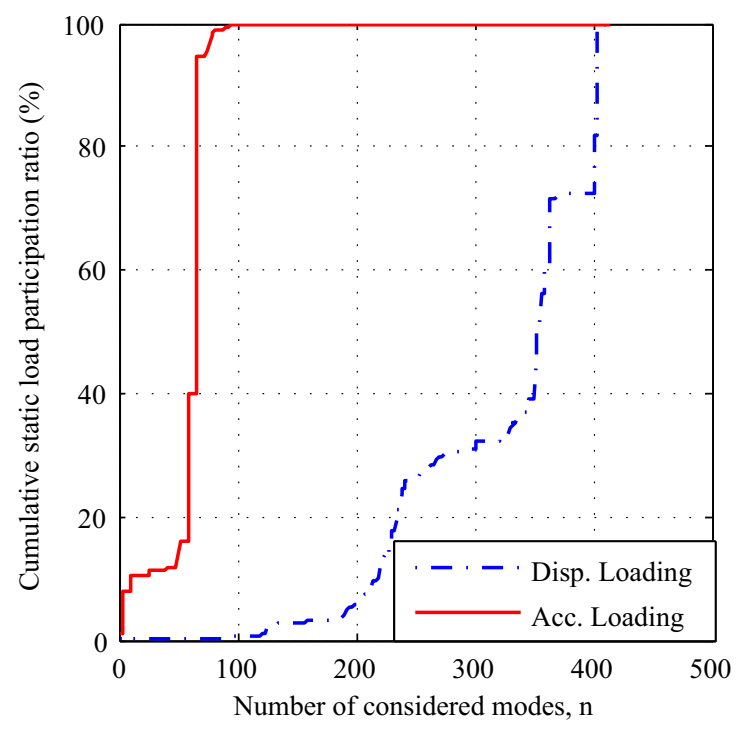

where $y^{t}(t)^{S C}=$ statically corrected displacement vector, and the second term on the right-hand side denotes the displacement response caused by the first $n$ modes.

\section{Finite-Element Model of the Bill Emerson Memorial Bridge}

The Bill Emerson Memorial Bridge is located in Cape Girardeau, Missouri (Fig. 1). It consists of two towers and one pier (Fig. 2), which are referred to as Piers II, III, and IV, respectively. The main span is $350.60 \mathrm{~m}$, and the end spans are $142.70 \mathrm{~m}$ long. The towers are connected to the deck by 128 cable elements. The outer ends of the deck are connected to Bent I and Pier IV. The connections in Bent I restrain the deck from vertical and lateral movements and allow longitudinal displacement and rotation about the vertical axis. The deck-to-tower connections in Piers II, III, and IV restrict the displacement in vertical and lateral directions and have lock-up devices that allow movement in the longitudinal direction only when caused by temperature changes. (The lock-up devices are not implemented in the finite-element model of this study; instead, the deck-to-pier connections restrain longitudinal movements, as do the lateral and vertical constraints.)

The finite-element model of the bridge was constituted in $M A T L A B$ to obtain an efficient dynamic simulation model, which was accomplished by following the modeling technique proposed by Wilson and Gravelle (1991). In the finite-element model (Fig. 3), the deck and piers are represented as beam elements, and cables are represented as truss elements. Each construction joint of the bridge is selected as a node for the deck-and-pier models. The deck is modeled as a spinal beam with lumped masses, as shown in Fig. 4, to obtain an equivalent polar moment of inertia of the bridge deck. A rigid link used in this model consists of multipoint constraints among the two outer nodes. Deck-cable and cable-tower connections were established by using the rigid links (Fig. 4). Deck-tower connections in Piers II, III, and IV were constituted by using kinematic constraints in which displacements of the deck and tower were equal in the $x, y$, and $z$ directions at the deck-tower connection point. A static condensation procedure was applied to reduce the DOF. The finite-element model consists of 45 support DOF and 415 structural DOF.

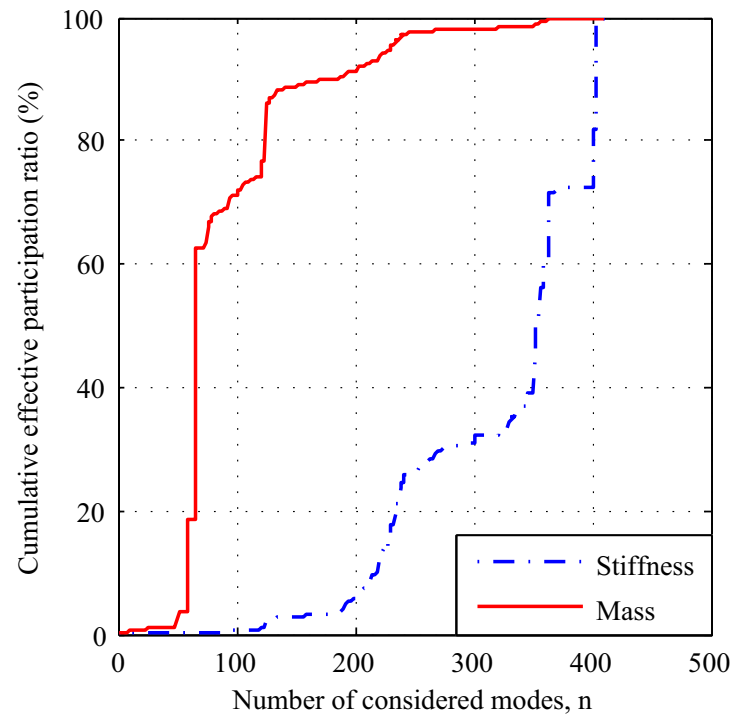

Fig. 6. Cumulative participation ratios in the longitudinal direction (Note: Disp. $=$ displacement; Acc. $=$ acceleration) 
Free-vibration mode shapes based on the finite-element models of the Bill Emerson Memorial Bridge are shown in Fig. 5. Modes 4, 5 , and 6 have frequencies with differences of less than $10 \%$, which implies that coupling will take place during broadband excitations such as earthquakes. Natural frequencies of the bridge obtained in this and earlier studies are provided in Table 1 . The differences between the current study and that of Turan et al. (2009) lie in the member-stiffness formulations. The current study evaluates the member-stiffness matrices with an in-house software program, whereas the Turan et al. (2009) study incorporated the memberstiffness matrices from an Abaqus static analysis and assembled them by using the same in-house software used in this study.

Fig. 6 shows the variations in cumulative static load and effective participation ratios of displacement and acceleration loadings attributable to a uniform unit excitation along the bridge's longitudinal direction. These participation ratios help to determine the sufficient number of modes to be taken into account in the dynamic analysis. The higher modes show greater participation than the lower modes in displacement loading, which is a finding opposite that of acceleration loading. As seen in Fig. 6, according to the criterion of $90 \%$ static-load participation for acceleration loading, the sufficient mode number should be 65 . In contrast, 185 modes are required to satisfy the criterion of $90 \%$ mass participation. In addition, these criteria are satisfied if 405 modes are taken into account for displacement loading. The variations of cumulative static-load and effective stiffness participation ratios are the same. However, to obtain a realistic solution, nearly all vibration modes should be considered. For this reason, a static correction procedure is required in the displacement loading to reduce the required number of modes in the analysis.

\section{Numerical Analysis and Discussion}

A dynamic analysis of the Bill Emerson Memorial Bridge with prescribed support displacements is carried out here. The effect of multisupport displacement and acceleration loading together with
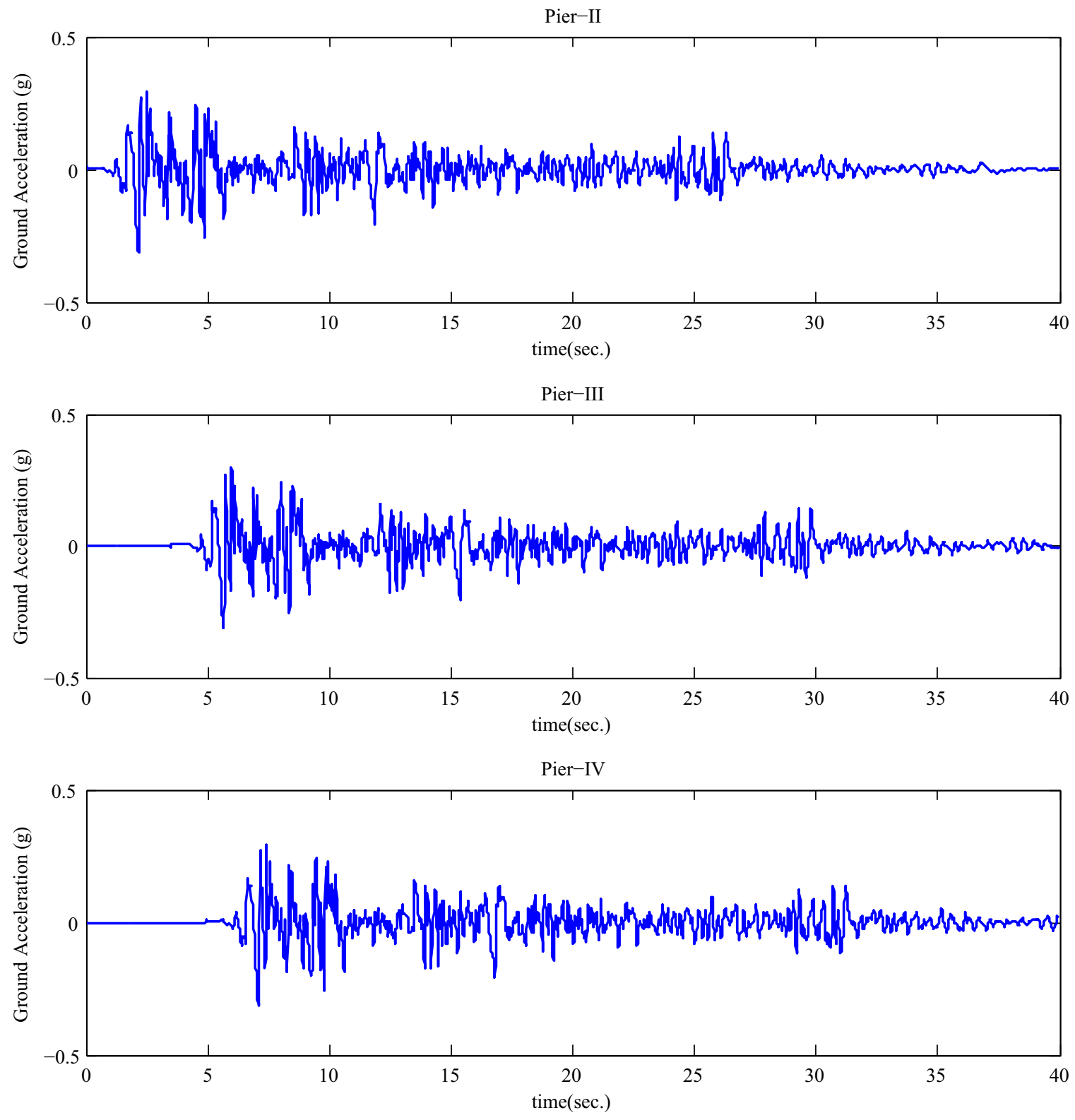

Fig. 7. Ground-acceleration data for Piers II, III, and IV 
damping is investigated. Simulations that involve modal and Rayleigh damping are compared in the analyses.

The 1940 El Centro earthquake record is used for the simulation of this bridge. To relate the presented cumulative static-load participation ratio from a single input to the shear force response, only the North-South component of ground-motion data is prescribed for the longitudinal direction of Piers II, III, and IV with time delays. These delays are calculated by assuming the traveling velocity of the earthquake wave at $100 \mathrm{~m} / \mathrm{sec}$ under the assumption of soft soil (Yilmaz 2015). This speed is much lower than the 3,000-m/sec wave speed adopted by Caicedo et al. (2003) in their benchmark control study. The displacement and velocity data of these records (Fig. 8) are obtained by integrating ground acceleration data given in Fig. 7.

The damping matrix is constructed through two different approaches. The first approach assumes modal damping. Here, the effect of three different modal damping ratios, 2, 10, and 20\%, are considered. Although 10 and $20 \%$ damping ratios might not seem
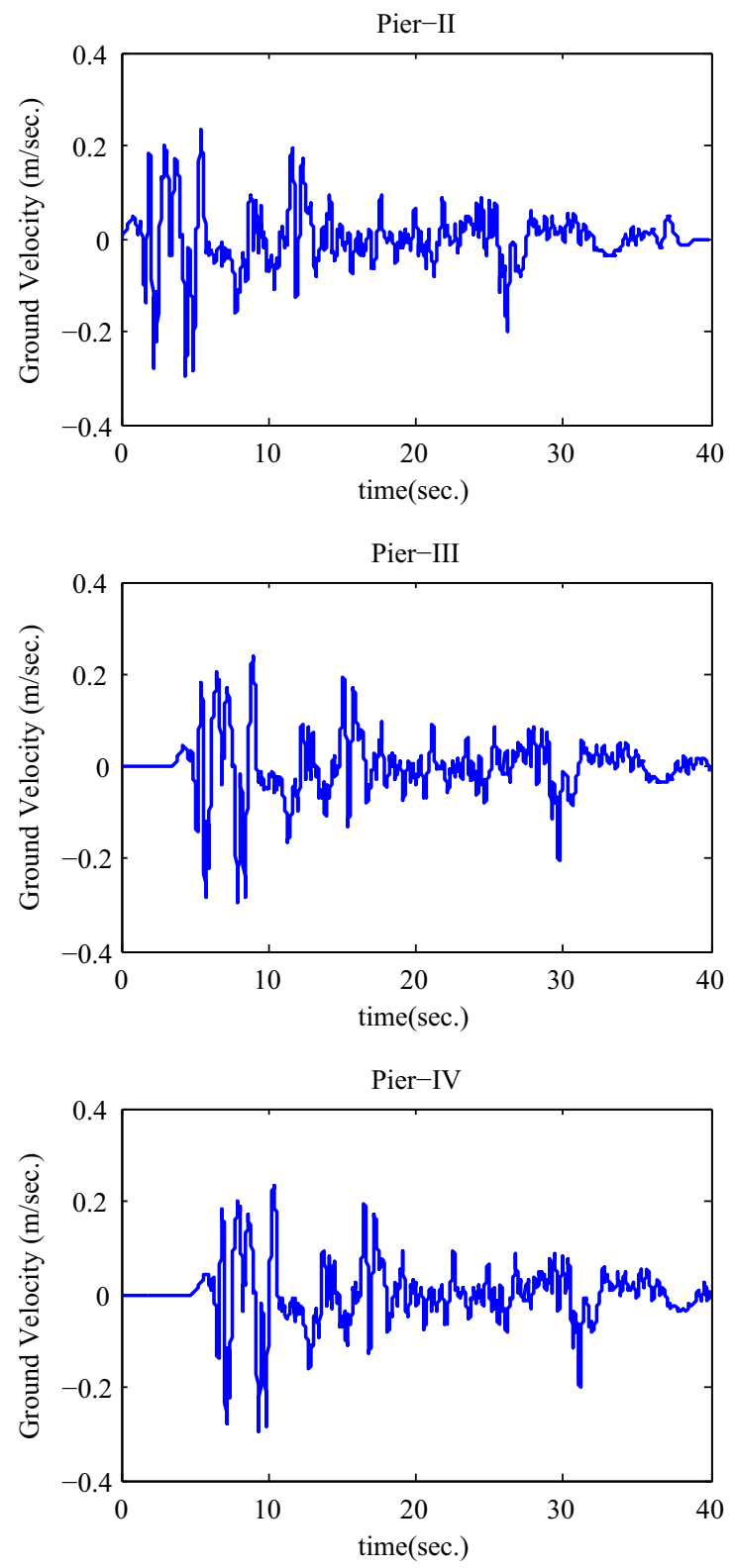

reasonable for current standing-bridge structures, these ratios enable one to pinpoint the differences in the responses with respect to the chosen damping matrix models. The damping matrix of the unconstrained DOF was constructed from a reverse calculation of the modal damping values, as follows (Chopra 2013):

$$
C=M\left(\sum_{i=1}^{N} \frac{2 \xi_{i} \omega_{i}}{\bar{M}_{i}} \Phi_{i} \Phi_{i}^{T}\right) M
$$

In the second approach, a simple Rayleigh damping model is assumed. This approach is considered simple, because a directional separation of the modes is not considered (Chopra 2013).

$$
C=\alpha_{0} M+\alpha_{1} K
$$

where $\alpha_{0}$ and $\alpha_{1}=$ proportional constants of mass and stiffness matrices, which can be computed by using Eq. (38)
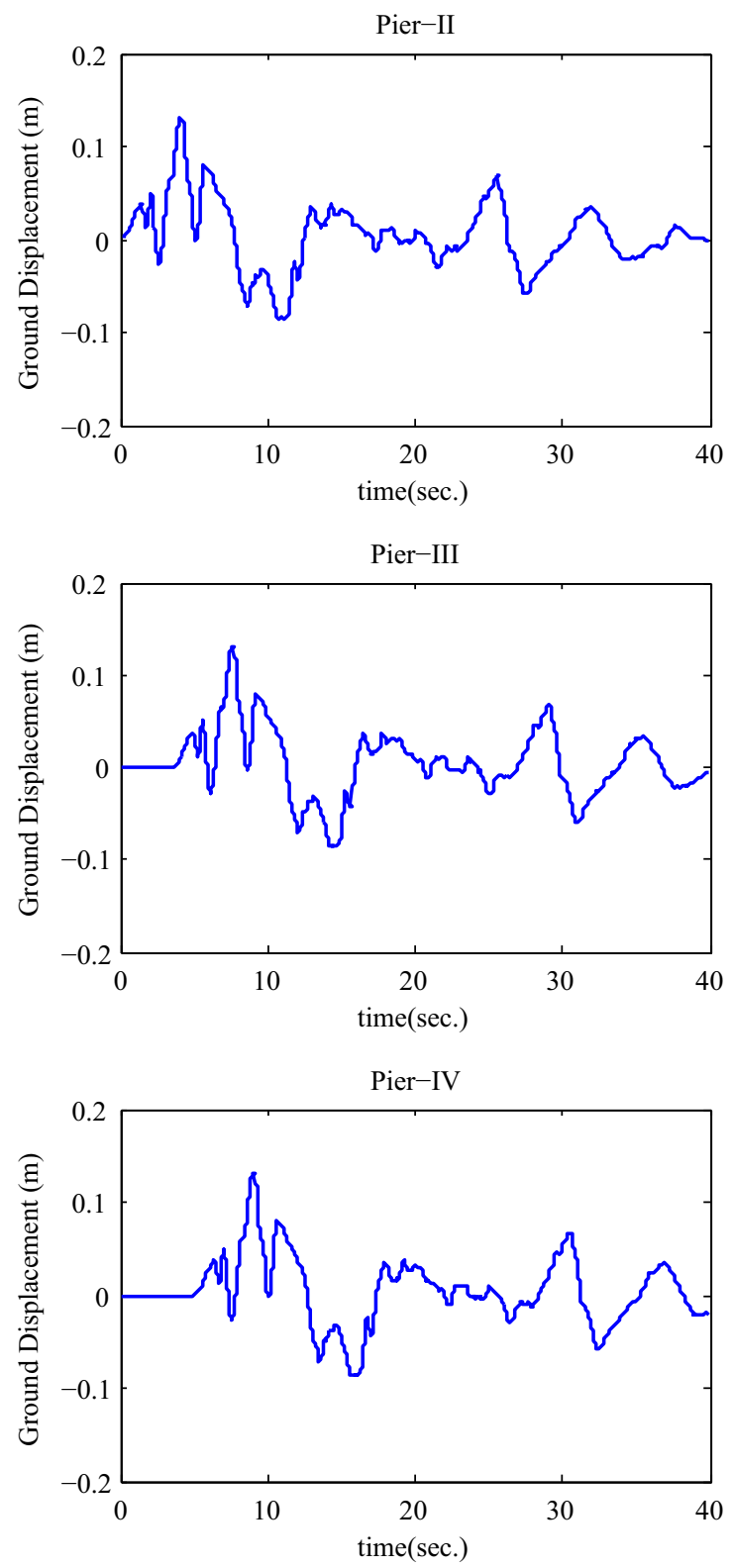

Fig. 8. Ground-displacement and -velocity data for Piers II, III, and IV 


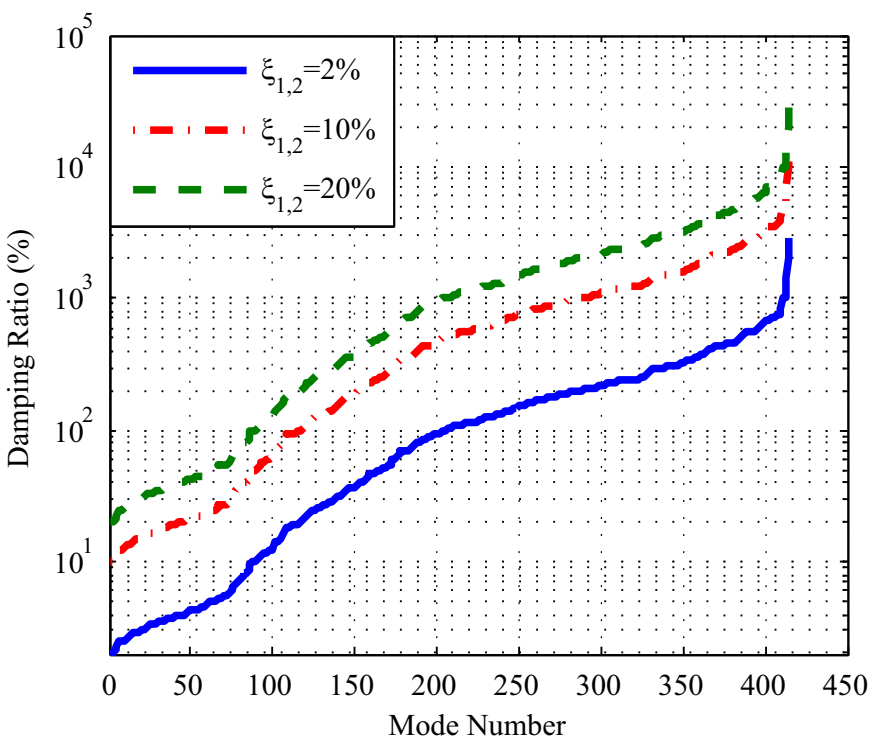

Fig. 9. Variations in Rayleigh damping ratio versus mode number

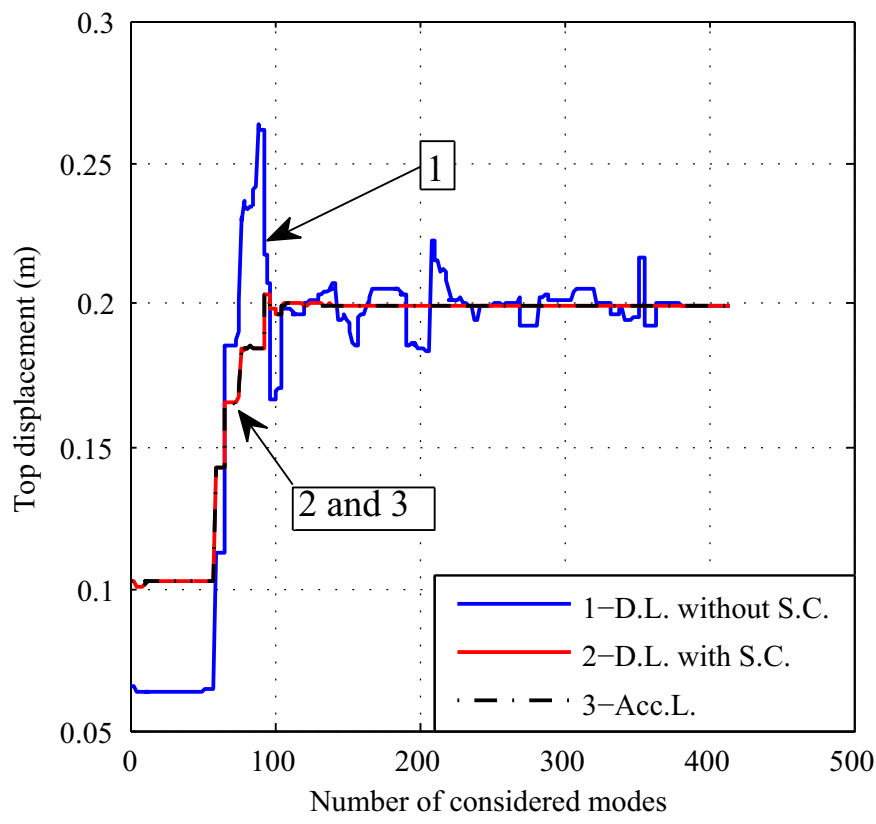

Fig. 10. Variations in top displacements of Pier III (undamped case) (Note: D.L. = displacement loading; S.C. = static correction; Acc.L. = acceleration loading)

$$
\begin{aligned}
\alpha_{0} & =\frac{2 \xi_{1,2} \omega_{1} \omega_{2}}{\omega_{1}+\omega_{2}} \\
\alpha_{1} & =\frac{2 \xi_{1,2}}{\omega_{1}+\omega_{2}}
\end{aligned}
$$

where $\xi_{1,2}, \omega_{1}$, and $\omega_{2}=$ damping ratio and natural angular frequencies of the first two modes, respectively. The natural angular frequencies $\omega_{1}$ and $\omega_{2}$ are calculated from Table 1 , and $\xi_{1}$ is assumed to be equal to $\xi_{2}$. Again, three different damping matrices are obtained for $\xi_{1,2}$ (i.e., 2, 10, and 20\%). The calculated Rayleigh damping ratios for the vibration modes are presented in Fig. 9, which shows that modes higher than 205,117 , and 88 are overdamped for $\xi_{1,2}=2,10$, and $20 \%$, respectively.
Figs. 10-13 show the variations in the top displacement of Pier III versus the considered mode numbers for modal and Rayleigh damping. At first view, differences between the displacement response of displacement loading and displacement-velocity loading for the damped cases, $\xi=10$ and $20 \%$, can be seen. These differences are measured as 4\% [Fig. 12(b)] and 8\% [Fig. 13(b)] for Rayleigh damping, which correspond to $\xi_{1,2}=10$ and $20 \%$, respectively. For modal damping, the approximate differences are $0.8 \%$ [Fig. 12(a)] and 1.6\% [Fig. 13(a)] for $\xi_{1,2}=10$ and 20\%, respectively. According to these figures, all maximum displacement values converge to the exact value when more modes are considered, but to acquire responses without static correction requires many more modes to be considered. A large error in maximum displacement values without static correction is present when fewer than 100 modes are considered. The variance decreases as a higher number of modes are considered for both modal and Rayleigh damping analyses. The maximum top displacement of Pier III shows fluctuations in the uncorrected responses for uniform excitation as the number of considered modes increases. The fluctuations for both modal and Rayleigh damping are similar, and they both damp out rapidly. Note that, for the undamped case shown in Fig. 10, displacement-velocity loading and displacement loading result in the same response because the ground velocity is ineffective.

The ground motion results in a force, $F_{g}(t)$, that is transferred from the base system to the superstructure. The elastic forces of constrained DOF, which involve the base shear force, overturning moment, and base axial force of Piers II, III, and IV, can be calculated by using Eq. (39).

$$
f_{g}(t)=K_{g}^{T} y^{t}(t)+K_{g g} y_{g}(t)
$$

Substituting the first row of Eq. (8) into Eq. (39) results in

$$
f_{g}(t)=K_{g}^{T} y(t)+f_{g}^{s}(t)
$$

where

$$
f_{g}^{s}(t)=\left(K_{g}^{T} \ell+K_{g g}\right) y_{g}(t)
$$

In this case, $f_{g}^{s}(t)$ denotes the pseudostatic support reactions and dominates the response of Eq. (40) with the application of static correction. The contribution of the first term, which depends on the structural relative displacements, is on the order of $0.1 \%$ of the total response, as can be seen in Fig. 14. If static correction is not applied and an insufficient number of modes is selected in the calculation, then the effect of the first term in Eq. (40) constitutes $150 \%$ of the exact value.

The variation of the maximum base shear force of Pier III attributable to displacement loading and displacement-velocity loading versus the considered mode numbers are presented in (Figs. 15-18) for modal (with $\xi=0,2,10$, and 20\%) and Rayleigh (with $\xi_{1,2}=0$, 2,10 , and 20\%) damping. It can be seen that the maximum base shear force, $V_{b, \max }$, which is obtained without the application of static correction, is as much as $60 \%$ larger than the correct value. By using the first 380 mode shapes, the exact value of the maximum base shear force is obtained. In contrast, the exact value can be obtained with one mode by applying the static correction method. In this particular calculation, the exact base shear in the longitudinal direction of the bridge is found exactly by using only the first mode. This one-mode approximation is the result of $f_{g}^{s}(t)$ being the governing term in Eq. (40). In this case, the pseudostatic displacement happens to be dominant over that caused by the structural vibration. Therefore, a one-mode calculation for the base shear force seems 


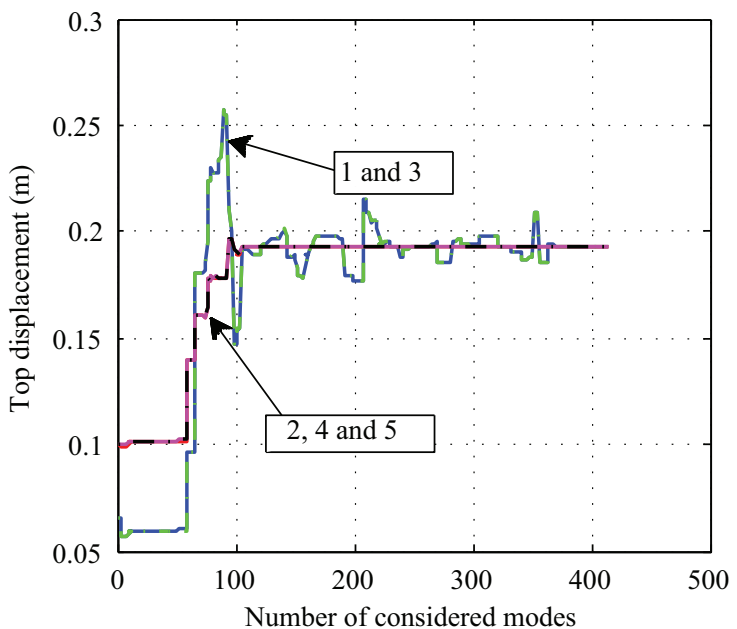

(a)

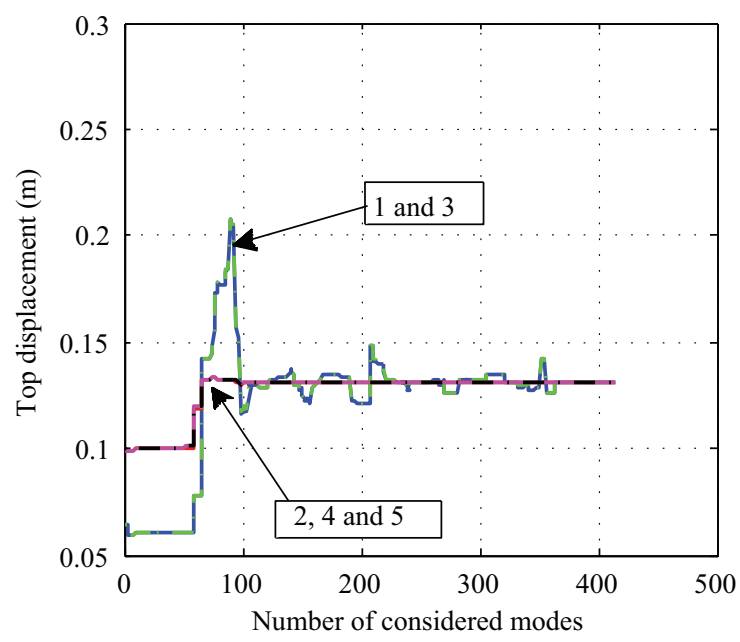

(b)

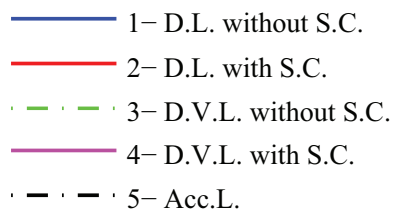

Fig. 11. Variations in top displacements of Pier III: (a) modal damping $(\xi=2 \%)$; (b) Rayleigh damping $\left(\xi_{1,2}=2 \%\right)($ Note: D.V.L. $=$ displacementvelocity loading)

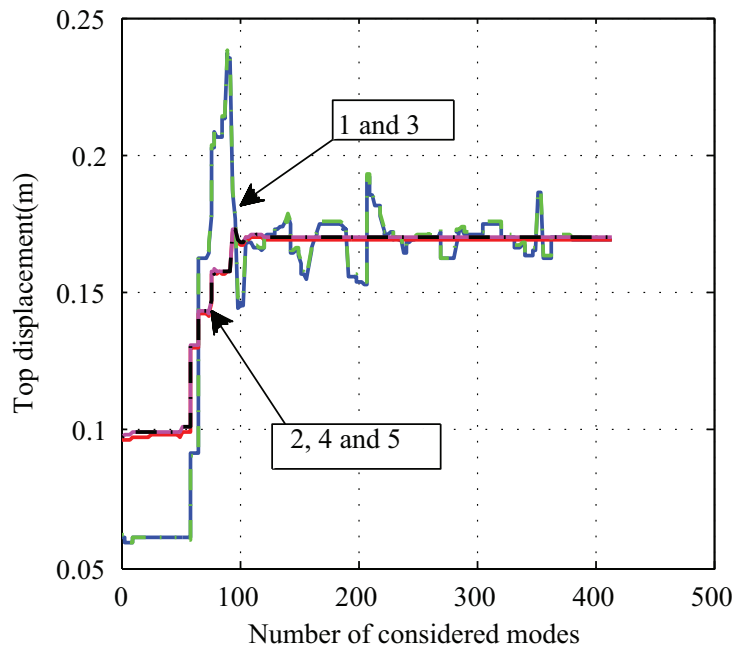

(a)

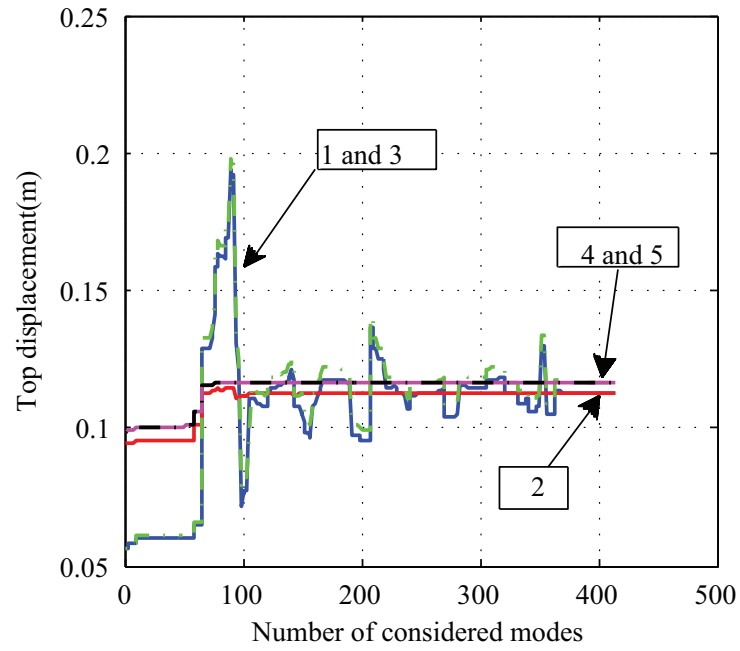

(b)

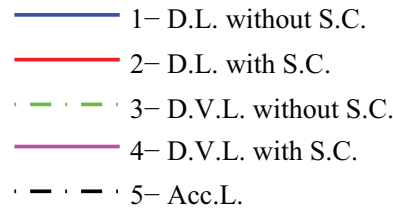

Fig. 12. Variations in top displacements of Pier III: (a) modal damping $(\xi=10 \%)$; (b) Rayleigh damping $\left(\xi_{1,2}=10 \%\right)$

sufficient. On the contrary, more than 100 modes are required for variations in $y_{\max }^{S C}$ and $y_{\max }$ to be tolerable (Figs. 10-13). For this reason, the static correction method should be used for the calculation of internal forces when displacement-type loading is considered. In addition, for the Rayleigh-damping approach, an error up to $4 \%$ is observed for displacement loading, starting at the 200th mode, and this error does not diminish when all modes are considered. This phenomenon is not observed in the displacementvelocity loading because it is associated with the stiffness proportional part of the coupled damping matrix, $C_{g}$. In addition, the base shear forces obtained for displacement loading and displacementvelocity loading are similar for the modal damping case, but a difference is observed in the displacement response as mentioned earlier. This effect might depend on the structural model. 


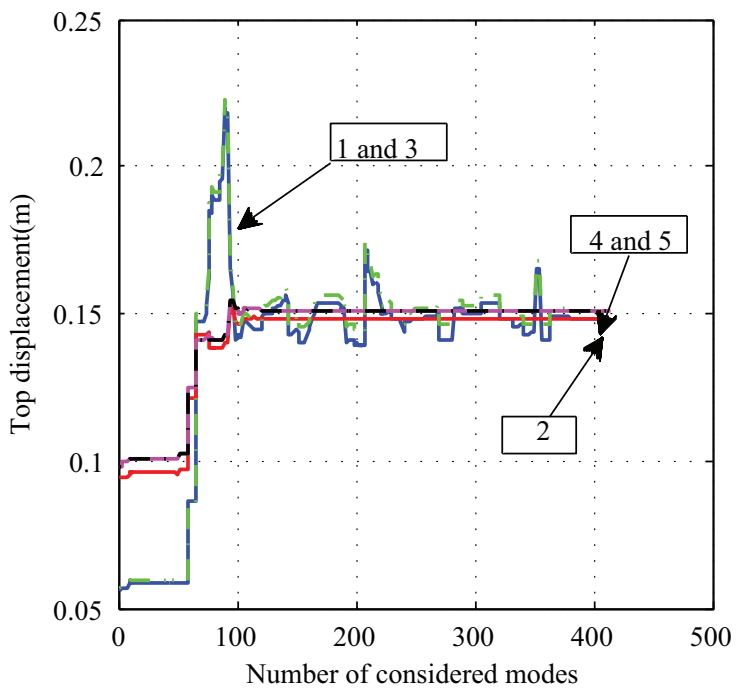

(a)

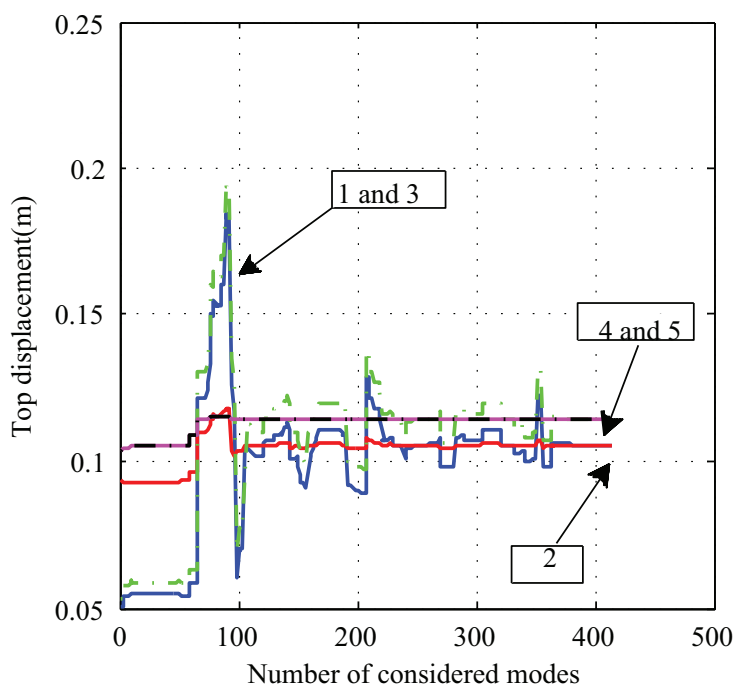

(b)

$$
\begin{aligned}
& \text { - 1- D.L. without S.C. } \\
& \text { - 2- D.L. with S.C. } \\
& \text { - - 3- D.V.L. without S.C. } \\
& \text { 4- D.V.L. with S.C. } \\
& \text { - . - 5- Acc.L. }
\end{aligned}
$$

Fig. 13. Variations in top displacements of Pier III: (a) modal damping $(\xi=20 \%)$; (b) Rayleigh damping $\left(\xi_{1,2}=20 \%\right)$

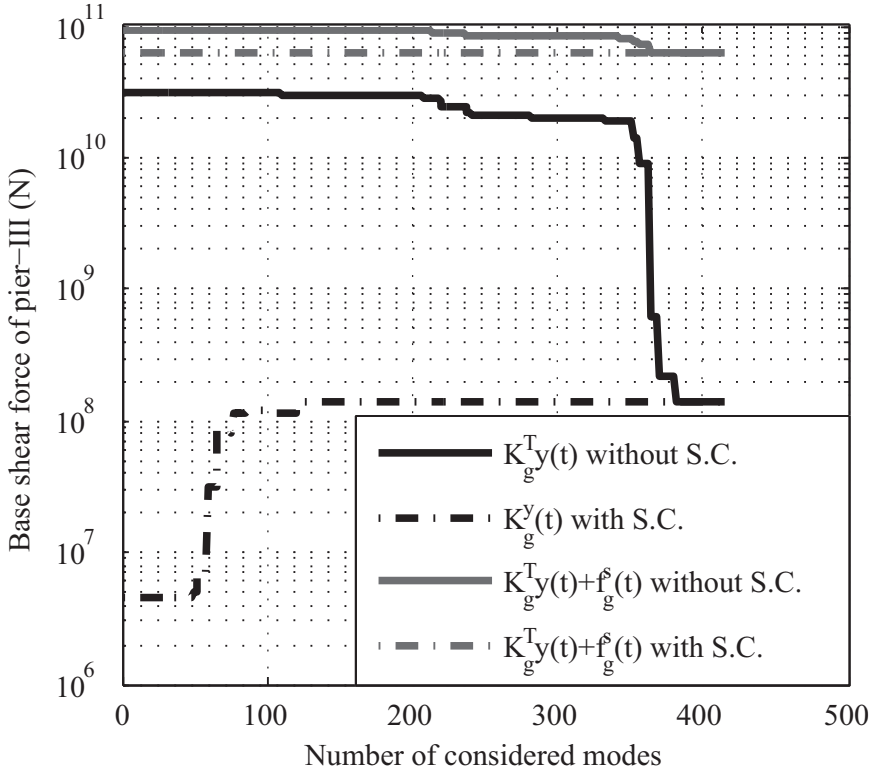

Fig. 14. Effect of $f_{g}^{s}(t)$ on variations in base shear force of Pier III (undamped case)

According to Figs. 14-18, the widely used cumulative effective mass participation ratio that is shown in Fig. 6(a) does not reflect the modal base shear force response that is obtained by acceleration loading. Similarly, variations in the cumulative static-load participation ratio [Fig. 6(b)] are not compatible with variations in the corresponding base shear force. These differences might be explained by the pseudostatic effect, $f_{g}^{s}(t)$, which dominates the base shear force response but is not considered in the calculation of participation ratios. In contrast, the cumulative effective stiffness participation ratio reveals the same trend as the modal variations of the base

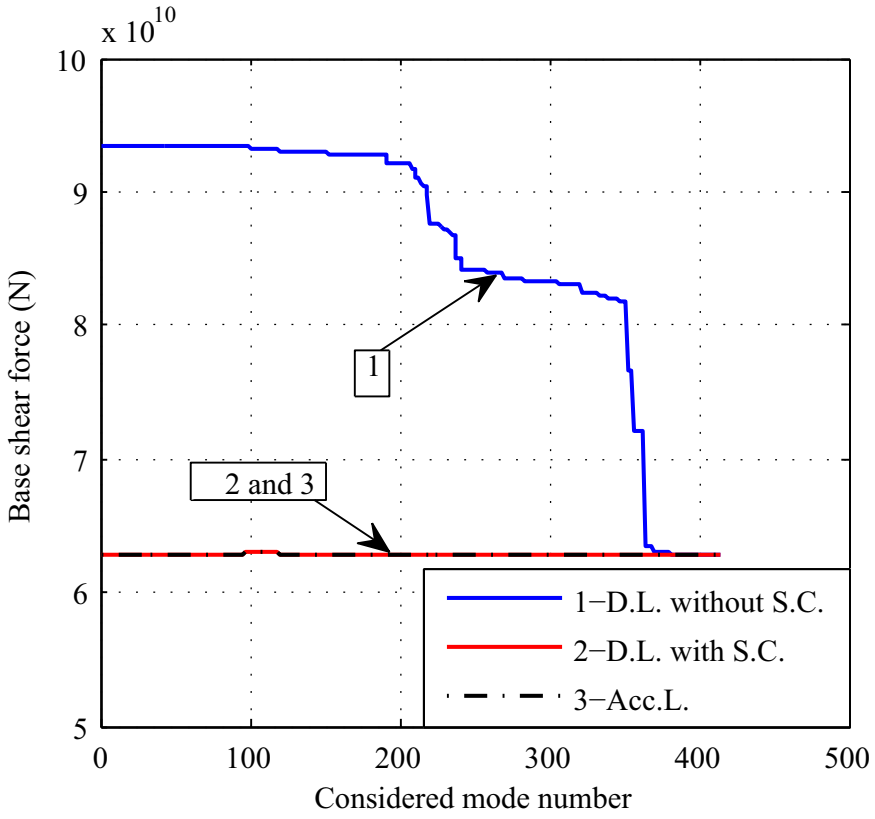

Fig. 15. Variations in base shear force of Pier III (undamped case)

shear force obtained without static correction. Because $f_{g}^{s}(t)$ is not dominant on the modal base shear force obtained without static correction, the cumulative effective stiffness participation ratio helps to determine the number of required modes.

\section{Conclusions}

In this study, application of the static correction method in displacement loading with and without velocity input was investigated and 


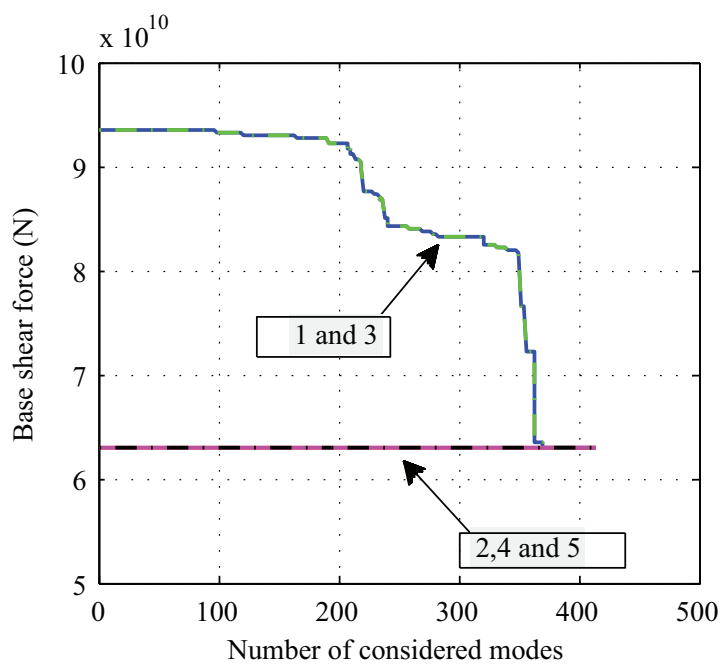

(a)

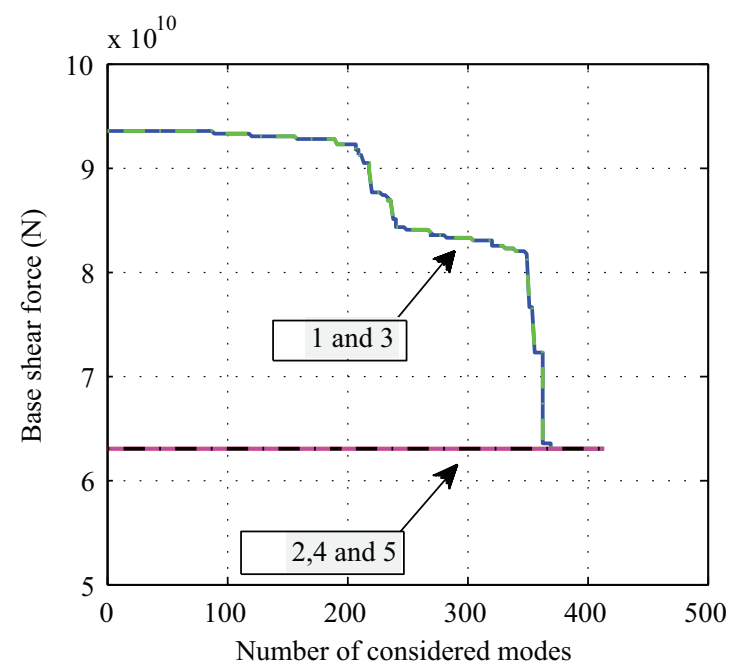

(b)

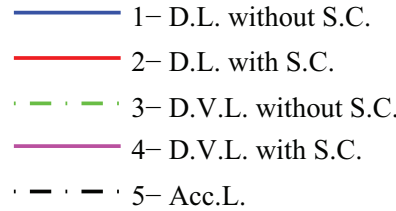

Fig. 16. Variations in base shear force of Pier III: (a) modal damping $(\xi=2 \%)$; (b) Rayleigh damping $\left(\xi_{1,2}=2 \%\right)$

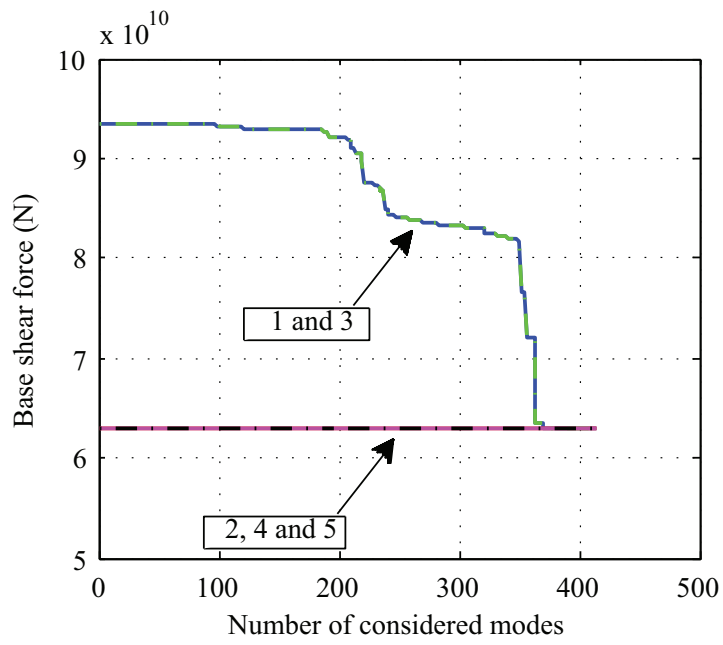

(a)

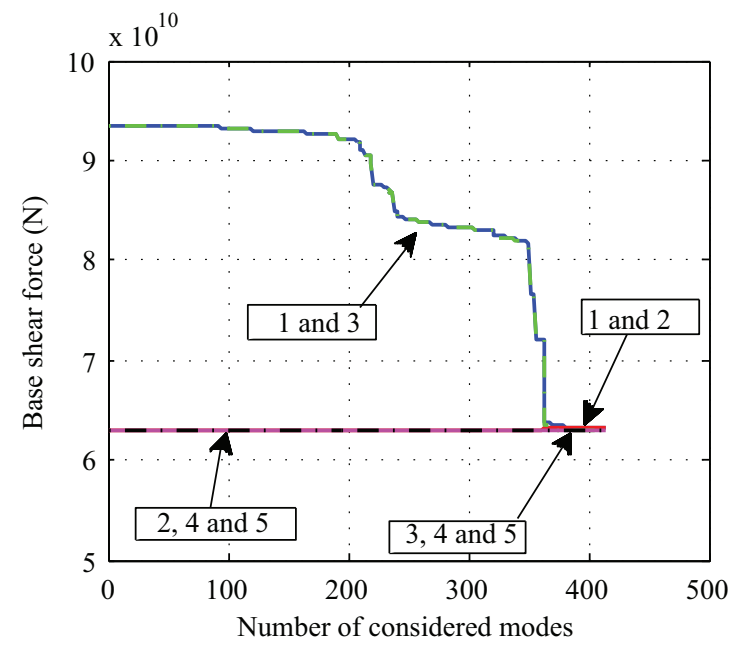

(b)

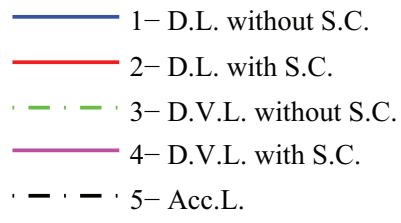

Fig. 17. Variations in base shear force of Pier III: (a) modal damping ( $\xi=10 \%)$; (b) Rayleigh damping $\left(\xi_{1,2}=10 \%\right)$

numerically applied to a finite-element model of the Bill Emerson Memorial Bridge. In addition, the effects of the increasing damping ratios on the convergence analysis results are were investigated. The convergences of the modal displacement and base shear force obtained with and without application of the static correction method were presented.

The nature of the problem in displacement loading lies in the structural absolute displacements, which are a combination of structural dynamic response and structural deformation caused by support displacement (pseudostatic displacements). In modal analysis, the absolute dynamic response was disintegrated into its modal components. In this case, the selected number of modes was considered for the structural and pseudostatic displacements. However, the pseudostatic displacement of the structure does not depend on mode frequency; instead, it relies on the full set of modal shapes that represent the required pseudostatic structural 


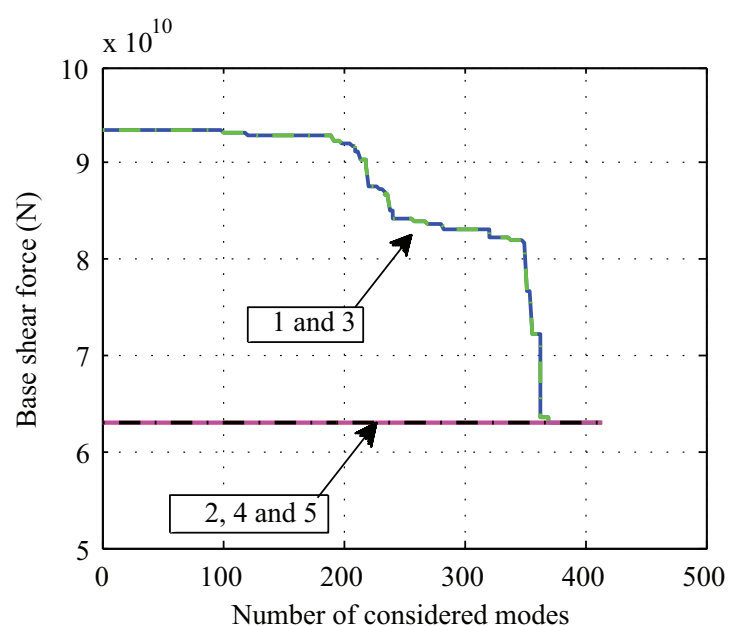

(a)

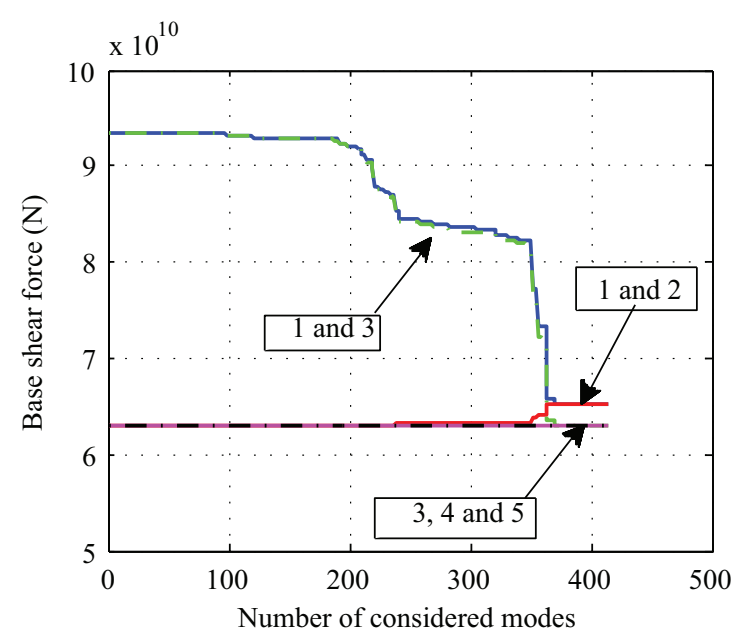

(b)

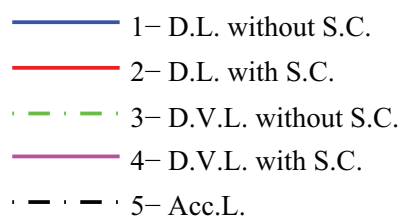

Fig. 18. Variations in base shear force of Pier III: (a) modal damping $(\xi=20 \%)$; (b) Rayleigh damping $\left(\xi_{1,2}=20 \%\right)$

configurations. Thus, the effect of the unconsidered modes for the pseudostatic displacement must be reintegrated into the structural response. The following conclusions summarize the findings of this study:

- In multiple-support excitation with relative response values of structural DOF (acceleration loading), the structural pseudostatic displacements must be added to the solution. This is an essential part that can be overlooked when absolute structural displacements are not sought.

- The displacement responses obtained without applying static correction approach the expected value when few modes are considered, but it oscillates around this value with an error up to $15 \%$ when more modes are considered. The exact value is reached when high-frequency modes are also considered in the analysis. This error persists under various damping ratios.

- The base shear forces without static correction are affected much more than the displacement responses. Convergence is obtained only when the considered mode numbers are very close to the total number of modes.

- Dynamic responses obtained for displacement loading with static correction converges to the responses based on acceleration loading.

- The $90 \%$ participation requirement of cumulative static load and effective mass for acceleration loading is based on the base shear force accumulation with an increasing number of modes for regular-type buildings. However, a three-dimensional bridge has a response that is very different than that of a regular building; therefore, one should use a sufficient number of modes depending on the response value of interest. The required number of modes might change significantly for different response values of the bridge.

- In displacement loading without static correction, the cumulative static-load and effective stiffness participation ratio provide direct information on the base shear force.
- Damping causes an error in the displacement response if the velocity term in the displacement loading is neglected. This error is similar for modal and Rayleigh damping.

- The base shear force does not seem to be affected when modal damping is considered. However, an error is observed for Rayleigh damping caused by a number of high-frequency modes, which can be associated with the stiffness proportional part of the coupled damping matrix, $C_{g}$.

\section{References}

Abaqus [Computer software]. SIMULIA, Providence, RI.

Abdel Raheem, S. E., Hayashikawa, T., and Dorka, U. (2011). "Ground motion spatial variability effects on seismic response control of cablestayed bridges." Earthquake Eng. Eng. Vib., 10(1), 37-49.

Caicedo, J. M., Dyke, S. J., Moon, S. J., Bergman, J. A., Turan, G., and Hague, E. A. (2003). "Phase II benchmark control problem for seismic response of cable-stayed bridges." Struct. Control Health Monit., 10(3-4), 137-168.

Chopra, A. K. (2013). Dynamics of structures theory and applications, 4th Ed., Prentice Hall, Upper Saddle River, NJ.

Cui, P. J., and Gao, D. F. (2011). "Travelling wave effect analysis of longspan cable-stayed bridge.” Adv. Mat. Res., 243-249, 308-312.

De Mari, G., Domaneschi, M., Ismail, M., Martinelli, L., and Rodellar, J. (2015). "Reduced-order coupled bidirectional modeling of the Roll$\mathrm{N}-\mathrm{Cage}$ isolator with application to the updated bridge benchmark." Acta Mech., 226(10), 3533-3553.

Domaneschi, M., and Martinelli, L. (2014). "Extending the benchmark cablestayed bridge for transverse response under seismic loading." J. Bridge Eng., 10.1061/(ASCE)BE.1943-5592.0000532, 04013003.

Dyke, S. J., Caicedo, J. M., Turan, G., Bergman, L. A., and Hague, S. (2003). "Phase I benchmark control problem for seismic response of cable-stayed bridges." J. Struct. Eng., 10.1061/(ASCE)0733 -9445(2003)129:7(857), 857-872.

Du, X. T., Xu, Y. L., and Xia, H. (2012). "Dynamic interaction of bridgetrain system under non-uniform seismic ground motion." Earthquake Eng. Struct. Dyn., 41(1), 139-157. 
Frýba, L., and Yau, J. D. (2009). "Suspended bridges subjected to moving loads and support motions due to earthquake." J. Sound Vib., 319(1-2), 218-227.

Jiao, C., Li, A., Wu, X., and Dong, X. (2013). "Seismic response analysis of a double-deck long-span cable-stayed bridge under multi-support excitations." J. Chin. Inst. Eng., 36(3), 314-334.

Koh, B. H., and Dyke, S. J. (2007). "Structural health monitoring for flexible bridge structures using correlation and sensitivity of modal data." Comput. Struct., 85(3-4), 117-130.

Li, J., and Yang, Q. (2008). "Seismic responses analysis of long continuous rigid-framed bridge subjected to multi-support excitations." Proc., 14th World Conf. on Earthquake Engineering, China Earthquake Administration and Ministry of Construction, Beijing, China.

Li, Y. G., Fan, F., and Hong, H. P. (2014). "Effect of support flexibility on seismic responses of a reticulated dome under spatially correlated and coherent excitations." Thin Walled Struct., 82(Sep), 343-351.

MATLAB [Computer software]. MathWorks, Natick, MA.

Soyluk, K. (2004). "Comparison of random vibration methods for multisupport seismic excitation analysis of long-span bridges." Eng. Struct., 26(11), 1573-1583.

Surh, H.-B., et al. (2015). "Seismic response analysis of a piping system subjected to multiple support excitations in a base isolated NPP building." Nucl. Eng. Des., 292(Oct), 283-295.

Su, L., Dong, S., and Kato, S. (2007). "Seismic design for steel trussed arch to multi-support excitations." J. Constr. Steel Res., 63(6), 725-734.

Tian, Y., and Yang, Q. (2009). "On time-step in structural seismic response analysis under ground displacement/acceleration." Earthquake Eng. Eng. Vib., 8(3), 341-347.
Tsai, H. C. (1998). "Modal superposition method for dynamic analysis of structures excited by prescribed support displacements." Comput. Struct., 66(5), 675-683.

Turan, G., Voulgaris, B., and Bergman, L. A. (2009). "Earthquake response control of a cable-stayed bridge by using $\mu$-synthesis." Teknik Dergi, 20(4), 4865-4889.

Wang, H., Li, J., Tao, T., Wang, C., and Li, A. (2015). "Influence of apparent wave velocity on seismic performance of a super-long span tripletower suspension bridge." Adv. Mech. Eng., 7(6), 1-4.

Wang, Z., and Kiureghian, A. D. (2014). "Multiple-support response spectrum analysis using load-dependent Ritz vectors." Earthquake Eng. Struct. Dyn., 43(15), 2283-2297.

Wilson, E. L. (2002). Three-dimensional static and dynamic analysis of structures, Computers and Structures, Inc., Berkeley, CA

Wilson, J. C., and Gravelle, W. (1991). "Modeling of a cable-stayed bridge for dynamic analysis." Earthquake Eng. Struct. Dyn., 20(2), 707-721.

Yau, J. D. (2009). "Dynamic response analysis of suspended beams subjected to moving vehicles and multiple support excitations." J. Sound Vib., 325(4-5), 907-922.

Yau, J. D., and Frýba, L. (2007). "Response of suspended beams due to moving loads and vertical seismic ground excitations." Eng. Struct., 29(12), 3255-3262.

Ye, J., Zhang, Z., and Liu, X. (2012). "A simplified multi-support response spectrum method.” Earthquake Eng. Eng. Vib., 11(2), 243-256.

Yilmaz, Ö. (2015). Engineering seismology with applications to geotechnical engineering, Society of Exploration Geophysicists, Tulsa, OK.

Zhang, Y. H., Li, Q. S., Lin, J. H., and Williams, F. W. (2009). "Random vibration analysis of long-span structures subjected to spatially varying ground motions." Soil Dyn. Earthquake Eng., 29(4), 620-629. 